\title{
Sitagliptin/metformin fixed-dose combination in type 2 diabetes mellitus: an evidence-based review of its place in therapy
}

This article was published in the following Dove Press journal:

Drug Design, Development and Therapy

19 July 2016

Number of times this article has been viewed

\author{
Jennifer Hayes' \\ Rosie Anderson' \\ Jeffrey W Stephens ${ }^{1,2}$ \\ 'Department of Diabetes and \\ Endocrinology, Morriston Hospital, \\ ABM University NHS Trust, ${ }^{2}$ Diabetes \\ Research Group, Institute of Life \\ Sciences, Swansea University, \\ Swansea, UK
}

\begin{abstract}
Type 2 diabetes mellitus is a progressive disease associated with significant morbidity and mortality. There is good evidence showing that intensive glycemic control reduces the development and progression of complications. In order to achieve glycemic targets, patients often require a combination of oral therapy and/or insulin in addition to lifestyle modification. Unfortunately, many of the traditional therapies for type 2 diabetes are associated with weight gain and hypoglycemia, resulting in poor compliance and subsequent worsening of glycemic control. The dipeptidyl peptidase- 4 inhibitor sitagliptin is a therapy for type 2 diabetes and is available as a fixed-dose combination with metformin. Phase III clinical trials have demonstrated beneficial effects on glycemic control and minimal untoward effects with this combination. In this article, we provide an overview of the pharmacology, efficacy, and safety and examine the role of this combination within current practice.
\end{abstract}

Keywords: sitagliptin, metformin, fixed-dose combination, type 2 diabetes

\section{Introduction}

Achieving a glycated hemoglobin (HbA1c) level of $<7.0 \%$ is the primary end point of diabetic care, with evidence supporting this target for the reduction of microvascular complications and providing potential benefit to the macrovascular complications of diabetes. ${ }^{1}$ The complex pathophysiology of diabetes, with a combination of peripheral insulin resistance, reduced insulin production secondary to beta-cell dysfunction, and increased hepatic gluconeogenesis, provides a number of potential treatment targets. The British National Institute for Health and Care Excellence (NICE), the American Diabetes Association (ADA), and the European Association for the Study of Diabetes (EASD) recommend early intervention with oral antidiabetic agents to obtain the target HbA1c. ${ }^{1,2}$ Type 2 diabetes mellitus is a chronic and progressive disease, and although monotherapy may be adequate initially, $>50 \%$ of patients do not achieve adequate glycemic control. ${ }^{3}$ Dose adjustment and progression to multiple diabetes therapies are often required to maintain target $\mathrm{HbA} 1 \mathrm{c}$ levels.

Metformin, a biguanide, is recommended as the first-line oral hypoglycemic agent by NICE, the ADA, and the EASD and can be used for monotherapy and combination therapy. ${ }^{1,4}$ Metformin has a number of complementary but not yet fully understood mechanisms of action. The accepted mechanism of action is a reduction in hepatic glucose output, but it also increases peripheral glucose utilization, increases peripheral tissue sensitivity to insulin, decreases fatty acid oxygenation, and reduces intestinal carbohydrate absorption. ${ }^{4}$ It is the most widely prescribed first-line therapy
Correspondence: Jeffrey W Stephens Department of Diabetes and Endocrinology, Morriston Hospital, ABM University NHS Trust, Heol Maes Eglwys, Swansea SA6 6NL, UK Tel +44 I792 704078

Fax +44 I792 703214

Email j.w.stephens@swansea.ac.uk 
and is associated with relatively low adverse effects such as hypoglycemia and weight gain. Metformin has a low acquisition cost and can be used safely in combination with other oral agents and insulin. ${ }^{4}$ Despite its initial efficacy in HBA1c reduction, with increased duration of type 2 diabetes, other agents are often required to maintain and improve glycemic control. In recent years, newer agents such as the dipeptidyl peptidase-4 inhibitors (DDP-4i) have provided an add-on option to metformin. Breakthroughs in the understanding of incretin-based therapy have provided a novel and exciting approach in the management of type 2 diabetes during the past 15 years. ${ }^{5}$ The incretin effect is the exaggerated insulin release seen following an oral glucose load compared to intravenous administration, which is believed to be due to release of hormones within the gastrointestinal tract when a meal is ingested. These hormones, known as incretins, work to stimulate glucosedependent insulin secretion from beta cells by intracellular signaling pathways including cyclic adenosine monophosphate. ${ }^{5}$ In addition, these short-acting hormones suppress hepatic glucagon secretion, and delays gastric emptying in a glucose-dependent manner. The two best studied incretins are glucagon-like peptide 1 (GLP-1) and glucose-dependent insulinotropic polypeptide. ${ }^{5}$ It has also been proposed that the incretins have a beneficial effect on beta-cell mass, with animal studies demonstrating beta-cell proliferation and reduced apoptosis after treatment with GLP-1. ${ }^{6}$ GLP-1 is metabolized rapidly by proteolytic cleavage by the enzyme DDP-4. Patients with type 2 diabetes may have reduced levels of GLP-1 in response to a glucose load, suggesting a potential target area for treatment. ${ }^{5}$ DDP-4i act to delay endogenous degradation of incretins, resulting in a twofold to threefold increase in the circulating levels of glucose-dependent insulinotropic polypeptide and GLP-1. ${ }^{5}$ The effect is to promote glucose-dependent biosynthesis and release of insulin, resulting in better glycemic control. ${ }^{7}$ The first in this class was sitagliptin, receiving European Medicines Agency approval in 2007, licensed for both monotherapy and combination therapy, including with metformin. In the UK, it is licensed for monotherapy in combination with diet and exercise in those with contraindications or who cannot tolerate metformin and as a triple therapy with metformin plus sulfonylureas or thiazolidinediones. Sitagliptin is associated with a low risk of hypoglycemia due to its glucose-dependent mechanism, is weight neutral, and has a low adverse effect profile in addition to its positive effect on the metabolic abnormalities associated with type 2 diabetes. ${ }^{8}$ Metformin and sitagliptin provide an attractive initial combination therapy due to their complementary mechanisms of action, targeting more than one pathophysiological defect in type 2 diabetes. Sitagliptin increases glucose-dependent insulin secretion, while metformin reduces hepatic gluconeogenesis and sensitizes peripheral tissues to the action of insulin. Beyond this, coadministration of sitagliptin and metformin has been shown to produce additive enhancement of active GLP-1 levels relative to the individual agents. ${ }^{5}$ Studies in healthy volunteers of the combination of sitagliptin and metformin have shown a doubling of active postprandial GLP-1 levels, which is fourfold greater than metformin or sitagliptin alone. ${ }^{9}$ It is thought that they act through different but complementary mechanisms, with metformin increasing the release and sitagliptin inhibiting active GLP-1 degradation. Single tablet combination therapy has been developed (fixed-dose combinations [FDCs]) to take advantage of these complementary actions while reducing tablet burden. The aim of this review is to evaluate the clinical utility of a FDC of sitagliptin/metformin in the treatment of type 2 diabetes.

\section{Pharmacokinetic and pharmacodynamic properties of metformin and sitagliptin \\ Metformin}

Metformin hydrochloride ( $N, N$-dimethylimidodicarbinimidic diamide hydrochloride) is a derivative of guanidine, with a molecular formula of $\mathrm{C}_{4} \mathrm{H}_{11} \mathrm{~N}_{5} \mathrm{HCl}^{10}$ It has been found to have saturable and incomplete oral bioavailability of $40 \%-60 \%$. The absorption is reduced and delayed in the presence of food. ${ }^{4}$ Metformin is distributed without binding to plasma proteins and primarily undergoes renal excretion unchanged ${ }^{10}$ with the remaining $20 \%-30 \%$ recovered in the feces. A significant increase in plasma half-life is seen in patients with renal impairment, and it is not indicated for use in patients with an estimated glomerular filtration rate $<30 \mathrm{~mL} / \mathrm{min} / 1.73 \mathrm{~m} .{ }^{2,4}$ The mean plasma half-life is estimated to be $4-8.7$ hours.

\section{Sitagliptin}

Sitagliptin, MK-0431 [(2R)-4-oxo-4-(3-[trifluoromethyl]5,6-dihydro[1,2,4]triazolo[4,3-a]pyrazin-7[8H]-yl)-1(2,4,5-trifluorophenyl)butan-2-amine], ${ }^{6}$ is an orally active beta-amino acid-derived DDP-4i, with molecular formula $\mathrm{C}_{16} \mathrm{H}_{20} \mathrm{~F}_{6} \mathrm{~N}_{5} \mathrm{O}_{6} \mathrm{P}$ and a molecular weight of $523.3 \mathrm{~g} / \mathrm{mol} .{ }^{11} \mathrm{It}$ is a potent inhibitor of DPP-4 (inhibition mean of $91.3 \%$ after 12 hours $^{3}$ ), with a half-life of $\sim 8-14$ hours and an oral bioavailability of $87 \%$ with negligible effect on the time to reach 
maximum concentration $\left(\mathrm{t}_{\max }\right)$ when administered with food. The mean plasma area under the curve of sitagliptin is $8.52 \mu \mathrm{M} / \mathrm{h}$ with a maximum concentration of $950 \mathrm{nM}$ with $\sim 38 \%$ plasma protein bound. ${ }^{7}$ Sitagliptin is primarily eliminated renally via active tubular secretion, $79 \%$ being excreted unchanged. Near maximal DPP-4 inhibition is seen at the recommended sitagliptin dose of $100 \mathrm{mg} / \mathrm{d} .{ }^{9}$

\section{Combined pharmacokinetic profile}

The limited studies available have shown no clinically meaningful alteration to the steady-state pharmacokinetics of sitagliptin and metformin either by coadministration as a FDC or when concomitantly administered. ${ }^{12}$

\section{Efficacy studies with sitagliptin and metformin combination}

Several studies have examined the efficacy, safety, and tolerability of sitagliptin and metformin as either a FDC or a dual therapy against placebo, monotherapy, as add-on, or other active combinations. Due to the vast array of evidence, this review will focus on the large ( $>500$ patients) randomized double-blind control trials available in the literature. Smaller and single-blind studies have supported the findings presented. ${ }^{13-15}$ A number of studies have examined the effect of the combined use of metformin and sitagliptin in relation to beta-cell function, which show a greater positive effect on beta-cell function compared to respective monotherapy. 5,16,17 These studies are summarized in Table 1.

\section{Sitagliptin and metformin as fixed dose or dual therapy compared to monotherapy}

Reasner et $\mathrm{al}^{18}$ assessed the efficacy and safety of sitagliptin/ metformin FDC therapy with metformin alone for $>18$ weeks and 26 weeks in treatment naive participants with type 2 diabetes who had an $\mathrm{HbA} 1 \mathrm{c} \geq 7.5 \%$ on a diet and exercise therapy. A total of 1,450 patients, aged 18-78 years of age with a mean $\mathrm{HbA} 1 \mathrm{c}$ of $9.9 \%$, were randomized to sitagliptin/metformin 50/500 mg or metformin $500 \mathrm{mg}$ monotherapy (up-titrated for $>4$ weeks to achieve maximum doses of metformin $1,000 \mathrm{mg}$ for both arms). ${ }^{7}$ At week 18 , the adjusted mean changes (with 95\% confidence intervals [CIs]) from baseline HbA1c were $-2.4 \%(-2.5$, -2.2 ) for sitagliptin/metformin and $-1.8 \%(-0.8,-0.4)$ for metformin alone, resulting in a significant between-group difference of $-0.6 \%(P<0.001)$. A higher proportion of participants receiving sitagliptin/metformin achieved an HbA1c $<7.0 \%$ at 18 weeks (49.2\% vs $34.2 \%$, respectively, $P<0.001)$. Similarly, a higher proportion of participants in the sitagliptin/metformin group achieved an $\mathrm{HbA} 1 \mathrm{c}<6.5 \%$ at 18 weeks compared to metformin alone. For fasting plasma glucose (FPG) at week 18, sitagliptin/metformin had a larger decrease from baseline compared to the monotherapy group, resulting in a significant difference between the groups of $-0.9 \mathrm{mmol} / \mathrm{L}(P<0.001)$. Significantly greater improvements in measures of beta-cell function (Homeostasis Model Assessment of beta-cell function and proinsulin/insulin ratio) were observed in the sitagliptin/metformin group at 18 weeks, and reduction in body weight from baseline was comparable in both groups. The safety profile was similar in both groups with no meaningful differences observed in drug-related adverse experiences or discontinuation of treatment. The incidence of reported hypoglycemia was low and similar in the two groups $(2.1 \%$ sitagliptin/metformin group and $1.8 \%$ metformin monotherapy).

Williams-Herman et $\mathrm{al}^{19}$ assessed the efficacy and safety of sitagliptin and metformin as initial combination therapy and as monotherapy in a long-term 104-week extension study of patients with type 2 diabetes with inadequate glycemic control (HbA1c 7.5\%-11\%) treated with diet and exercise. The study was an extension study of 50 weeks following a 54-week initial double-blind study with those receiving active treatment on the initial study remaining on this and those receiving placebo being transferred and up-titrated to $1,000 \mathrm{mg}$ of metformin. A total of 517 participants received sitagliptin $100 \mathrm{mg}$ once a day (OD), metformin $500 \mathrm{mg}$ twice a day (BD), metformin 1,000 mg BD, sitagliptin $50 \mathrm{mg}$ BD plus metformin $500 \mathrm{mg}$ BD, or sitagliptin $50 \mathrm{mg}$ BD plus metformin 1,000 mg BD. At week 104, all active treatment arms showed a significant reduction in $\mathrm{HbA} 1 \mathrm{c}$ from baseline with the sitagliptin $50 \mathrm{mg}$ plus metformin 1,000 mg $\mathrm{BD}$ showing the greatest reduction at $-1.7 \%$, greater than either monotherapy. Similarly, a higher proportion of participants in this group achieved an $\mathrm{HbA} 1 \mathrm{c}<7 \%, 60 \%$ compared to $45 \%$ with metformin $1,000 \mathrm{mg}$ and $32 \%$ with sitagliptin $100 \mathrm{mg}$. The incidences of adverse experiences were similar with a low incidence of hypoglycemia reported in all groups in the study.

Goldstein et $\mathrm{al}^{20}$ assessed the efficacy and safety of sitagliptin and metformin as initial combination therapy and as monotherapy for $>24$ weeks in participants with inadequately controlled type 2 diabetes not receiving oral antihyperglycemic agents. A total of 1,090 participants, aged $18-78$ years, with a mean $\mathrm{HbA} 1 \mathrm{c}$ of $8.8 \%$, were randomized to receive sitagliptin $100 \mathrm{mg}$ OD, metformin $500 \mathrm{mg} \mathrm{BD}$, metformin $1,000 \mathrm{mg} \mathrm{BD}$, sitagliptin $50 \mathrm{mg}$ BD daily plus metformin $500 \mathrm{mg}$ BD, sitagliptin $50 \mathrm{mg}$ BD plus metformin $1,000 \mathrm{mg} \mathrm{BD}$, or placebo. At week 24, adjusted mean changes $(95 \% \mathrm{CI})$ from baseline HbA1c were highest in the 


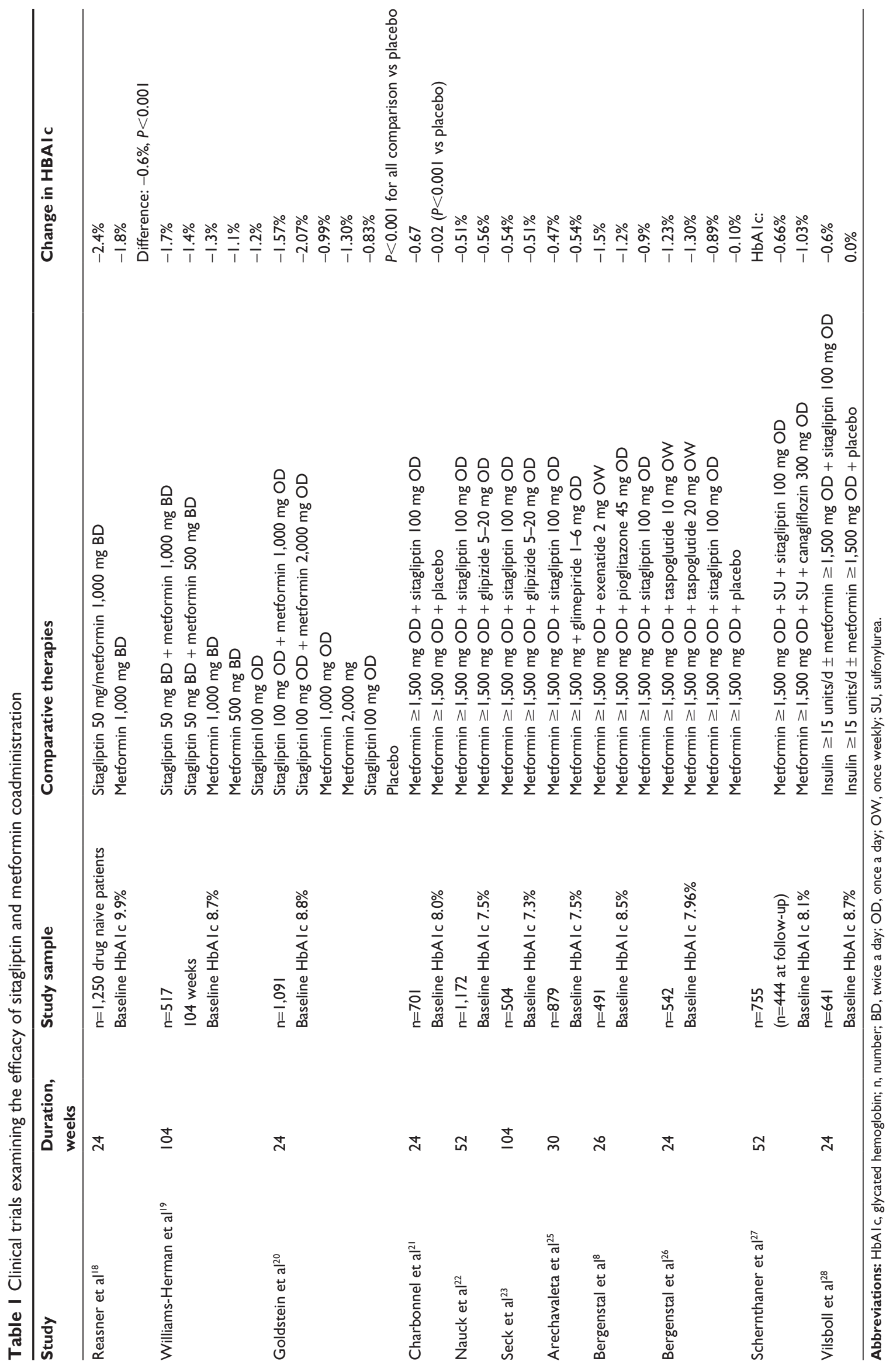


sitagliptin $100 \mathrm{mg}+$ metformin 2,000 mg group $(-1.90 \%$ [CI -2.06 to -1.84$]$ ) with all active treatment groups achieving significant changes $(P<0.001)$ in $\mathrm{HbAlc}$ from baseline relative to placebo (as shown in Table 1). Patients receiving sitagliptin + metformin at either dose were more likely to achieve an $\mathrm{HbA} 1 \mathrm{c}<7.0 \%$ and $<6.5 \%$ compared to monotherapy and placebo. All active treatment groups produced significant changes in FPG at 24 weeks compared to placebo. At 24 weeks, reductions in body weight were seen in all groups, except for sitagliptin, which showed no change from baseline.

Charbonnel et $\mathrm{al}^{21}$ compared the efficacy of sitagliptin in combination with metformin to metformin in combination with placebo in 701 patients with an $\mathrm{HbAlc}$ between 7\% and $10 \%$ on stable metformin doses of at least $1,500 \mathrm{mg} / \mathrm{d}$. Patients were randomized to add-on of $100 \mathrm{mg}$ sitagliptin OD or placebo for 24 weeks. Sitagliptin plus metformin provided effective and sustained improvement in glycemic control compared to placebo with an $\mathrm{HbAlc}$ reduction of $-0.67 \%$ from baseline and $\mathrm{FPG}$ reduction of $-0.9 \mathrm{mmol} / \mathrm{L}$, both statistically significantly greater than placebo. Once again, the addition of sitagliptin led to a significant increase in the proportion of patients achieving HbAlc $<7 \%$.

\section{Sitagliptin and metformin vs other agents and metformin}

Sitagliptin has been compared with a number of other oral hypoglycemic agents in combination with metformin primarily to provide evidence of noninferiority and to compare adverse effects. Nauck et $\mathrm{a}^{22}$ assessed the efficacy and safety of sitagliptin compared to glipizide as add-on therapy to metformin in patients with type 2 diabetes mellitus and suboptimal glycemic control on metformin alone. A total of 1,172 participants receiving metformin doses $\geq 1,500 \mathrm{mg} / \mathrm{d}$ were randomized to sitagliptin $100 \mathrm{mg}$ OD or glipizide, which was up-titrated from $5 \mathrm{mg}$ to $20 \mathrm{mg} / \mathrm{d}$ for 52 weeks. At 52 weeks, changes from baseline HbA1c were $-0.62 \%$ confirming noninferiority. The proportion of participants reporting hypoglycemic events was low in the sitagliptin with metformin group (4.9\%) and substantially higher in the glipizide with metformin group with 657 episodes of hypoglycemia reported by 187 patients (32.0\%). Furthermore, seven participants in the glipizide group required medical assistance for hypoglycemia compared to one in the sitagliptin group. Treatment with sitagliptin and glipizide was associated with an adjusted mean change in body weight from baseline of $-1.5 \mathrm{~kg}$ and $+1.1 \mathrm{~kg}$, respectively; the betweengroup difference was $-2.5 \mathrm{~kg}(P<0.001)$.
Seck et $\mathrm{al}^{23}$ conducted a 104-week trial examining glipizide 5-20 mg/d compared to sitagliptin $100 \mathrm{mg} / \mathrm{d}$, plus metformin $>1,500 \mathrm{mg} / \mathrm{d}$ with the primary outcome being $\mathrm{HbA} 1 \mathrm{c}$ reduction from 24 weeks to the end of 104 weeks. Of the 1,172 randomized patients, 504 completed 104 weeks. The dropout rate was similar in both groups. At 104 weeks, the mean change from baseline $\mathrm{HbA} 1 \mathrm{c}$ was $-0.51 \%$ for glipizide (256 participants) and $-0.54 \%$ for sitagliptin (248 participants). With respect to weight, there was a slight increase from week 24 for both sitagliptin $(0.16 \% / y r)$ and glipizide $(0.26 \% / \mathrm{yr})$. A similar proportion of participants achieved an $\mathrm{HbA} 1 \mathrm{c}<7 \%$ at the end of 104 weeks $(73 \%$ and $69 \%$ for sitagliptin and glipizide, respectively). The prevalence of medication-related adverse events were $16.5 \%$ and $33 \%$ for sitagliptin and glipizide, respectively, mainly due to episodes of hypoglycemia. Similar findings were seen in an extension to 54 weeks in a study by Karasik et al. ${ }^{24} \mathrm{~A}$ total of 544 participants completed the extension trial, and of those assigned to placebo were switched to glipizide and up-titrated from $5 \mathrm{mg}$ to $15 \mathrm{mg}$ as required. As with the Nauck et al study, ${ }^{22}$ similar changes in $\mathrm{HbA} 1 \mathrm{c}$ were reported, $-0.79 \%$ and $-0.9 \%$ for the sitagliptin and glipizide groups, respectively. Similar changes were reported between the sitagliptin and glipizide groups, for weight $-0.9 \mathrm{~kg}$ and $+1.1 \mathrm{~kg}$, respectively, and reported hypoglycemia $1 \%$ vs $16 \%$, respectively.

In a similar study, Arechavaleta et $\mathrm{al}^{25}$ assessed the efficacy and safety of sitagliptin compared to glimepiride as add-on therapy to metformin for $>30$ weeks in participants with type 2 diabetes mellitus and inadequate glycemic control receiving at least a 12-week course of metformin. A total of 879 participants were randomized to sitagliptin $100 \mathrm{mg}$ OD or glimepiride, which was up-titrated as required from $1 \mathrm{mg}$ to $6 \mathrm{mg}$ depending on the self-monitoring of blood glucose. Changes in $\mathrm{HbA} 1 \mathrm{c}$ from baseline were similar with $-0.46 \%$ metformin/sitagliptin and $-0.54 \%$ metformin/glimepiride with the between-group difference meeting the criteria for declaring noninferiority. The percentage of patients with an $\mathrm{HbAlc}<7.0 \%$ was slightly higher in the sitagliptin group but not statistically significant. The hazard of having symptomatic hypoglycemic events was calculated to be 15 -fold lower $(P<0.001)$ and 18 -fold lower $(P<0.001)$ as defined by selfmonitoring of capillary glucose measurements $\leq 3.9 \mathrm{mmol} / \mathrm{L}$ and $\leq 2.8 \mathrm{mmol} / \mathrm{L}$, respectively.

Bergenstal et $\mathrm{al}^{8}$ assessed the efficacy and safety of three oral hypoglycemics as added-on to metformin monotherapy in participants with inadequately controlled blood glucose in a double-blind, double-dummy controlled trial. These agents 
were sitagliptin, exenatide, and pioglitazone. A total of 491 patients were randomized to metformin $\geq 1,500 \mathrm{mg}$ plus sitagliptin $100 \mathrm{mg}$ OD plus once weekly (OW) injectable placebo, metformin 1,500 $\mathrm{mg}$ plus exenatide $2 \mathrm{mg}$ injected OW plus oral placebo, or metformin $\geq 1,500 \mathrm{mg}$ plus pioglitazone $45 \mathrm{mg}$ OD plus one weekly injectable placebo. At 26 weeks, the adjusted mean $\mathrm{HbA} 1 \mathrm{c}$ reduction from baseline was $-0.9 \%,-1.5 \%$, and $-1.2 \%$ for sitagliptin, exenatide, and pioglitazone, respectively. A statistically significant difference between exenatide and sitagliptin was noted. This was not the case for exenatide vs pioglitazone, where significantly more patients achieved HbA1c $<7 \%$ with exenatide than with sitagliptin or pioglitazone. No note is made comparing the efficacy of pioglitazone to sitagliptin, and noninferiority was not investigated for these agents. In all primary and secondary recorded outcomes, exenatide provided the greatest reported improvement. At week 26, fasting insulin and FPG were significantly improved with exenatide compared to pioglitazone and sitagliptin. Of interest, all therapies were associated with significant improvements in C-reactive protein and adiponectin. Weight loss was seen with both sitagliptin $(-0.8 \mathrm{~kg})$ and exenatide $(-2.3 \mathrm{~kg})$ but not with pioglitazone $(2.8 \mathrm{~kg})$ with statistically significant differences for exenatide vs both sitagliptin and pioglitazone $(-1.5 \mathrm{~kg}, P=0.0002$ and $-5.1 \mathrm{~kg}, P<0.0001$, respectively). The reported frequency of adverse events for all therapies was similar, with pioglitazone having the highest reported series events at $6 \%$. The most common adverse effect seen with sitagliptin was gastrointestinal, although higher rates of vomiting and diarrhea were reported with exenatide, with $24 \%$ and $18 \%$, respectively, compared to $10 \%$ for both with sitagliptin. There was no difference in the overall safety profile of the three therapies.

Bergenstal et $\mathrm{al}^{26}$ also studied the efficacy and safety of metformin and sitagliptin against taspoglutide (an injectable GLP-1 analogue, which was subsequently discontinued and did not receive regulatory approval). The study design comprised of metformin $\geq 1,500 \mathrm{mg}$ plus taspoglutide $10 \mathrm{mg}$ or $20 \mathrm{mg}$ OW plus oral placebo or sitagliptin once daily plus weekly injectable placebo. At 24 weeks, the HBA1c reductions were $-2.3 \%,-1.3 \%$, and $-0.89 \%$ for $10 \mathrm{mg}, 20 \mathrm{mg}$, and sitagliptin, respectively, with statistically significant mean treatment differences compared to sitagliptin. A greater proportion of participants with taspoglutide achieved an $\mathrm{HbA} 1 \mathrm{c}<7 \%$ and $<6.5 \%$, with significant reduction in FPG. There was also greater weight reductions associated with taspoglutide $(-1.8 \mathrm{~kg},-2.6 \mathrm{~kg}$ compared to sitagliptin $-0.9 \mathrm{~kg}$ ). Adverse effects were greater with taspoglutide and were mainly gastrointestinal (nausea $51.3 \%$, $57.8 \%$, and $17.4 \%$; vomiting $29.4 \%, 40.1 \%$, and $6.5 \%$; and diarrhea $17.1 \%, 15.1 \%$, and 5.4\%). A small increased risk of nasopharyngitis and upper respiratory tract infections was associated with sitagliptin.

\section{Sitagliptin and metformin as part of triple combination therapy}

Schernthaner et $\mathrm{al}^{27}$ assessed the safety and efficacy of canagliflozin (300 mg/d), a sodium glucose cotransporter 2 (SGLT2) inhibitor, compared to sitagliptin in patients inadequately controlled on metformin and sulfonylurea in a noninferiority study relative to canagliflozin. This was a 52-week study with 755 participants receiving metformin $\leq 1,500 \mathrm{mg}$ and sulfonylurea at the half-maximal labeled dose or more, with a baseline HbA1c 7\%-10.5\% (mean baseline HbA1c of $8.1 \%$ ). At 52 weeks, the HBA1c reductions were $-1.03 \%$ for canagliflozin and $-0.66 \%$ for sitagliptin with a mean difference $-0.37 \%$. Significantly greater reduction from baseline FPG was observed for canagliflozin compared to sitagliptin $(P<0.001)$ and a greater reduction in body weight for canagliflozin with a mean difference of $-2.8 \mathrm{~kg}(P<0.001)$. For canagliflozin, there was a higher rate of genital mycotic infections. The prevalence of hypoglycemia was similar (canagliflozin 43.2\% and sitagliptin 40.7\%).

Vilsboll et $\mathrm{al}^{28}$ studied the efficacy and safety of sitagliptin when added to insulin therapy with or without metformin. A total of 641 participants who were taking $\geq 15$ units/d alone or in combination with metformin $\geq 1,500 \mathrm{mg} / \mathrm{d}$ were recruited and were randomized to receive either sitagliptin $100 \mathrm{mg}$ OD or placebo. The mean baseline HbA1c was $8.7 \%$. The change in $\mathrm{HbA} 1 \mathrm{c}$ was $-0.6 \%$ for sitagliptin and $-0.0 \%$ for placebo. The incidence of symptomatic hypoglycemia was $16 \%$ for sitagliptin compared to $8 \%$ for placebo $(P=0.003)$. No significant differences were observed for other adverse effects such as nasopharyngitis, upper respiratory tract infections, and urinary tract infections, and there was no change in body weight.

\section{Safety and tolerability}

From the studies described, the coadministration of metformin and sitagliptin was generally well tolerated in any combination as a FDC or as add-on in up to 2 years of treatment. The most commonly reported side effects related to the combination were nasopharyngitis, urinary tract infections, upper respiratory tract infections, and gastrointestinal symptoms. These were similar to the adverse effect profiles seen with sitagliptin ${ }^{29}$ monotherapy, and it is well established that 
metformin is associated with gastrointestinal effects. ${ }^{4}$ There was only a small increase in nasopharyngitis and urinary tract infections seen with the combination compared to placebo with few studies reporting significant change. Blood pressure was monitored in a large number of studies, and the combination treatment seemed to have no notable effect.

Although an increased risk of pancreatitis has been reported to be potentially associated with the use of oral antihyperglycemic agents, notably DDP-4i, no reported cases were seen in trials presented here. The cause of pancreatitis with incretin-based therapy is not fully understood, and larger studies looking at acute pancreatitis risk with sitagliptin use have not found an association. ${ }^{30,31}$ Despite this, a number of postmarketing reports have been described, and current evidence is not sufficient to provide a definitive answer. ${ }^{30}$ It is recommended that patients should be monitored for signs of acute pancreatitis when sitagliptin is initiated (monotherapy or in combination) and when dose is increased.

As described, although metformin is considered as one of the safest oral hypoglycemic agents, it is not indicated for use in patients with chronic kidney disease (CKD) with an estimated glomerular filtration rate $\leq 30 / \mathrm{min} / 1.73 \mathrm{~m}^{2}$ due to the perceived risk of lactic acidosis. ${ }^{30,32}$ Sitagliptin, although requiring dose adjustment, can be prescribed in CKD of any severity including end-stage renal failure. ${ }^{33}$ No studies were identified in the literature that looked specifically at the risk of lactic acidosis with the combination of sitagliptin and metformin. None of the studies presented in this review describe instances of lactic acidosis.

\section{Hypoglycemia}

Although hypoglycemia was reported in the reviewed studies, no great increase in risk was seen unless in combination with a sulfonylurea or insulin. ${ }^{27,28}$ In comparison to metformin monotherapy, ${ }^{18-21}$ there were no increase in hypoglycemic episodes reported with the highest available clinical dose of both agents. Risk was shown to be reduced with the metformin and sitagliptin combination compared to metformin combination with glipizide and gliperimide..$^{8,22,23,25}$

\section{Patient perspective}

There is an approved FDC, single-pill combination therapy available (Janumet) to improve the glycemic control of adults with type 2 diabetes licensed in the UK. It is licensed for patients in whom metformin alone or in combination with a sulfonylurea, pioglitazone, or insulin does not have adequate glycemic control. ${ }^{34}$ It is available in one dose of sitagliptin (50 mg) and metformin (1,000 mg) and should be prescribed as one tablet twice daily. This preparation provides physicians the ability to improve glycemic control without increasing the pill burden for the patient and provides relief for patients with type 2 diabetes often treated with a number of other medications. The combination has been shown to have a relatively small adverse effect profile with a reduced risk of hypoglycemic events compared to other combinations of oral hypoglycemic therapies. Hypoglycemic events are an important factor to consider for all patients and in particular in the elderly and those with a known cardiovascular history as they can increase risks of falls and cardiovascular events. Studies indicate the combination is weight neutral, which is another benefit to the patient.

\section{Conclusion and place in therapy}

A number of therapeutic options are available for patients with inadequate glycemic control on metformin monotherapy. Six classes of oral hypoglycemic agents are available and patients' quality of life and safety need to be carefully considered when prescribing. This is especially important when prescribing in the elderly and those with comorbidities such as a cardiovascular history and CKD. The combination of sitagliptin and metformin has been shown to adequately lower $\mathrm{HbA} 1 \mathrm{c}$ to a greater extent than either agent alone, and this combination addresses different pathophysiological processes implicated in the pathogenesis of type 2 diabetes. The combination has been found to be safe and well tolerated and with the availability of a single-pill FDC provides ease of use and prescription. With a low risk of hypoglycemia, it has a clear role in the first- and second-line therapy of type 2 diabetes, although further studies are required to assess longterm effectiveness and safety.

\section{Disclosure}

The authors report no conflicts of interest in this work.

\section{References}

1. National Institute for Health and Care Excellence. Type 2 Diabetes in Adults: Management. 2015 NICE guideline (NG28). Available from: http://www.nice.org.uk/guidance/ng28?unlid=9428993482016126103 832. Accessed July 1, 2016

2. American Diabetes Association. Standards of medical care in diabetes 2016. Diabetes Care. 2016;39(suppl 1):S1-S106.

3. Herman G, Stevens C, Van Dyck K, et al. Pharmacokinetics and pharmacodynamics of sitagliptin, an inhibitor of dipeptidyl peptidase IV, in healthy subjects: results from two randomized, double-blind, placebocontrolled studies with single oral doses. Clin Pharmacol Ther. 2005; 78(6):675-688

4. Papanas N, Maltezis E. Metformin: a review of its use in the treatment of type 2 diabetes. Clin Med Ther. 2009;1:1367-1381.

5. Campbell RK. Clarifying the role of incretin-based therapies in the treatment of type 2 diabetes mellitus. Clin Ther. 2011;33(5):511-527. 
6. Perfetti R, Hui H. The role of GLP-1 in the life and death of pancreatic beta cells. Horm Metab Res. 2004;36(11-12):804-810.

7. Golightly LK, Drayana CC, McDermott MT. Comparative clinical pharmacokinetics of dipeptidyl peptidase-4 inhibitors. Clin Pharmacokinet. 2012;51(8):501-514.

8. Bergenstal RM, Wysham C, MacConell L, et al; DURATION-2 Study Group. Efficacy and safety of exenatide once weekly versus sitagliptin or pioglitazone as an adjunct to metformin for treatment of type 2 diabetes (DURATION-2): a randomised trial. Lancet. 2010;376(9739): 431-439.

9. Chwieduk CM. Sitagliptin/metformin fixed-dose combination: in patients with type 2 diabetes mellitus. Drugs. 2011;71(3):349-361.

10. National Center for Biotechnology Information. PubChem Compound Database; CID=4091. Available from: http://pubchem.ncbi.nlm.nih. gov/compound/4091. Accessed January 2016.

11. National Center for Biotechnology Information. PubChem Compound Database; CID=4369359. Available from: http:/pubchem.ncbi.nlm.nih. gov/compound/4369359. Accessed January 2016.

12. Herman GA, Bergman A, Yi B, Kipnes M; Sitagliptin Study 012 Group. Tolerability and pharmacokinetics of metformin and the dipeptidyl peptidase-4 inhibitor sitagliptin when co-administered in patients with type 2 diabetes. Curr Med Res Opin. 2006;22(10):1939-1947.

13. Raz I, Chen Y, Wu M, et al. Efficacy and safety of sitagliptin added to ongoing metformin in therapy in patients with type 2 diabetes. Curr Med Res Opin. 2008;24(2):537-550.

14. Brazg R, Xu L, Dalla MC, et al. Effect of adding sitagliptin, a dipeptidyl peptidase-4 inhibitor, to metformin on 24-hour glycemic control and B-cell function in patients with type 2 diabetes. Diabetes Obes Metab. 2007;9(2):186-193.

15. Aschner $\mathrm{P}$, Chan J, Owens $\mathrm{D}$, et al; EASIE investigators. Insulin glargine versus sitagliptin in insulin-naive patients with type 2 diabetes mellitus uncontrolled on metformin (EASIE): a multicentre, randomised openlabel trial. Lancet. 2012;379(9833):2262-2269.

16. Perfetti R, Hui H. The role of GLP-1 in the life and death of pancreatic beta cells. Horm Metab Res. 2004;36(11-12):804-810.

17. Williams-Herman D, Xu L, Teng R, et al. Effect of initial combination therapy with sitagliptin and metformin on B-cell function in patients with type 2 diabetes. Diabetes Obes Metab. 2012;14(1):67-76.

18. Reasner C, Olansky L, Seck T, et al. The effect of initial therapy with the fixed-dose combination of sitagliptin and metformin compared with metformin monotherapy in patients with type 2 diabetes mellitus. Diabetes Obes Metab. 2011;13(7):644-652.

19. Williams-Herman D, Johnson J, Teng R, et al. Efficacy and safety of sitagliptin and metformin as initial combination therapy and as monotherapy over 2 years in patients with type 2 diabetes. Diabetes Obes Metab. 2010;12(5):442-451.

20. Goldstein B, Feinglos M, Lunceford J, Johnson J, Williams-Herman D; Sitagliptin 036 Study Group. Effect of initial combination therapy with sitagliptin, a dipeptidyl peptidase-4 inhibitor, and metformin on glycemic control in patients with type 2 diabetes. Diabetes Care. 2007;30(8): 1979-1987.

21. Charbonnel B, Karasik A, Liu J, Wu M, Meininger G; Sitagliptin Study 020 Group. Efficacy and safety of the dipeptidyl peptidase-4 inhibitor sitagliptin added to ongoing metformin therapy in patients with type 2 diabetes inadequately controlled with metformin alone. Diabetes Care. 2006;29(12):2638-2643.
22. Nauck M, Meininger G, Sheng D, Terranella L, Stein PP; Sitagliptin Study 024 Group. Efficacy and safety of the dipeptidyl peptidase- 4 inhibitor, sitagliptin, compared with the sulfonylurea, glipizide, in patients with type 2 diabetes inadequately controlled on metformin alone: a randomized, double-blind, non-inferiority trial. Diabetes Obes Metab. 2007;9(2):194-206.

23. Seck T, Nauck M, Sheng D, et al. Safety and efficacy of treatment with sitagliptin or glipizide in patients with type 2 diabetes inadequately controlled on metformin: a 2-year study. Int J Clin Pract. 2010;64(5): $562-576$.

24. Karasik A, Wu M, Williams-Herman D, et al. Sitagliptin added to ongoing metformin therapy provides sustained glycemic control over 54 weeks, with a low incidence of hypoglycemia and with weight loss [abstract no. 523-P (plus poster)]. 67th Scientific Sessions of the American Diabetes Association; Jun 22-26, 2007; Chicago, IL, A139.

25. Arechavaleta R, Seck T, Chen Y, et al. Efficacy and safety of treatment with sitagliptin or glimepiride in patients with type 2 diabetes inadequately controlled on metformin monotherapy: a randomized, double-blind, non-inferiority trial. Diabetes Obes Metab. 2011;13(2): $160-168$.

26. Bergenstal R, Forti A, Chiasson JL, Woloschak M, Boldrin M, Balena R. Efficacy and safety of taspoglutide versus sitagliptin for type 2 diabetes mellitus (T-emerge 4 trial). Diabetes Ther. 2012;3(1):13.

27. Schernthaner G, Gross JL, Rosenstock J, et al. Canagliflozin compared with sitagliptin for patients with type 2 diabetes who do not have adequate glycemic control with metformin plus sulfonylurea: a 52-week randomized trial. Diabetes Care. 2013;36(9):2508-2515.

28. Vilsboll J, Rosenstock H, Jarvinen Y, et al. Efficacy and safety of sitagliptin when added to insulin therapy in patients with type 2 diabetes $\mathrm{T}$. Diabetes Obes Metab. 2010;12(2):167-177.

29. Januvia (sitagliptin) [package insert]. Whitehouse Station, NJ: Merck; 2011. Available from: http://www.merck.com/product/usa/ pi_circulars/j/januvia/januvia_pi.pdf. Accessed December 2015.

30. Li L, Shen J, Bala M, et al. Incretin treatment and risk of pancreatitis in patients with type 2 diabetes mellitus:systematic review and meta-analysis of randomised and non-randomised studies. BMJ. 2014;345:g2366.

31. Garg R, Chen W, Pendergrass M. Acute pancreatitis in type 2 diabetes treated with exenatide or sitagliptin. Diabetes Care. 2010;33(11): 2349-2354.

32. Heaf J. Metformin in chronic kidney disease: time for a rethink. Perit Dial Int. 2014;34(4):353-357.

33. Chan J, Scott R, Arjona Ferreira J, et al. Safety and efficacy of sitagliptin in patients with type 2 diabetes and chronic renal insufficiency. Diabetes Obes Metab. 2008;10(7):545-555.

34. Joint Formulary Committee [homepage on the Internet]. British National Formulary. London: BMJ Group and Pharmaceutical. Available from: www.medicinescomplete.com. Accessed January 2016.
Drug Design, Development and Therapy

\section{Publish your work in this journal}

Drug Design, Development and Therapy is an international, peerreviewed open-access journal that spans the spectrum of drug design and development through to clinical applications. Clinical outcomes, patient safety, and programs for the development and effective, safe, and sustained use of medicines are a feature of the journal, which
Dovepress

has also been accepted for indexing on PubMed Central. The manuscript management system is completely online and includes a very quick and fair peer-review system, which is all easy to use. Visit $\mathrm{http}: / /$ www.dovepress.com/testimonials.php to read real quotes from published authors. 